\title{
The Sentiments, Attitudes, and Concerns about Inclusive Education Revised (SACIE-R) Scale for Measuring Pre-Service Teachers' Perceptions about Inclusion
}

\author{
Chris Forlin \\ Hong Kong Institute of Education \\ Chris Earle \\ Tim Loreman \\ Concordia University College of Alberta \\ Umesh Sharma \\ Monash University
}

\begin{abstract}
This paper reports the final development of a scale to measure pre-service teachers' perceptions in three constructs of inclusive education, namely, sentiments or comfort levels when engaging with people with disabilities; acceptance of learners with different needs; and concerns about implementing inclusion. The Sentiments, Attitudes, and Concerns about Inclusive Education Revised (SACIE-R) scale was developed from an initial 60 items and administered through a series of refined surveys. A final 15-item scale was validated using 542 pre-service teachers from nine institutions in four countries including Hong Kong, Canada, India, and the United States. It is posited that the SACIE-R scale will yield valuable information for assisting universities and colleges in preparing more specific training to address the needs of pre-service teachers for working with diverse student populations.
\end{abstract}

An inclusive approach is understood as meaning that the education of all students covering the spectrum of diversity takes place in adequately supported regular classrooms in the educational context that would be attended if the form of diversity were not present, normally the neighbourhood school (Jordan, 2007). While originally focusing on the inclusion of students with specific disabilities - or learning difficulties as used in the United Kingdom-inclusion has increasingly become broadened to refer to catering for the needs of all children, including those who may be disenfranchised, vulnerable, from different cultures or ethnic groups, in poverty, or for any other reason find accessing the regular school challenging (see Calgary Board of Health, 2008, for a definition of diverse populations; Gause, 2011; Richards, Brown, \& Forde, 2009). The inclusion of all students in regular schools is a result of the international movement towards providing equal opportunities and access for all learners in the same schools whenever possible. The advent of the first World Conference on Education for All in Jomtein, Thailand (UNESCO, 1990), followed by the 
Dakar Framework for Action, Education for All: Meeting Our Collective Commitments at the World Education Forum at Dakar, Senegal (UNESCO, 2000), and the development of the powerful Salamanca Statement (UNESCO, 1994), reaffirmed that inclusive education represents the most equitable way of educating the majority of children in all countries.

The philosophy of educating children has gradually focused more on providing equal educational opportunities from a rights-based perspective, which has led to inclusive education continuing to be promoted and implemented to varying degrees in most regions over the past three decades. In some regions, inclusion has become embedded within legislation; for example, in the United States the Individuals with Disabilities Improvement Act (United States Department of Education, 2004) or within policy as in the United Kingdom the Code of Practice (Department for Education, 2001). Regarding the practicality of fully implementing inclusive education, many jurisdictions, though, continue to be reluctant to wholly support inclusion (Woolfson \& Brady, 2009). Indeed, in some instances there is very little support for inclusion (Alghazo \& Gaad, 2004), especially when learners have more challenging support needs (Talmor, Reiter, \& Feigin, 2005).

\section{Teacher Education for Inclusion}

Following this movement towards an inclusive educational approach in schools, teacher education has also had to undergo a major shift in its focus in order to prepare teachers for this change (Forlin, 2008; Forlin, 2010a). Alongside a standards-based reform in many regions, such as the United States, inclusion has challenged educators to achieve high standards for all students, including those with disabilities (Voltz \& Collins, 2010). Similarly, the expectation of the No Child Left Behind Act (Government of the United States of America, 2001) undoubtedly has had a high impact on pre-service teacher education in the United States (Harvey, Yssel, Bauserman \& Merbler, 2010). The most recent Article 24 of the Convention on the Rights of Persons with Disabilities (United Nation, 2006) articulated the right of persons with disabilities to education without discrimination and on the basis of equal opportunity. It also advanced the notion that professionals and staff must be trained to work at all levels of education and that "such training shall incorporate disability awareness and the use of appropriate augmentative and alternative modes, means and formats of communication, educational techniques and materials to support persons with disabilities" (UNESCO, 2006, Article 24, 4).

\section{Attitudes Towards Inclusion}

Understanding pre-service teachers' beliefs about inclusion is important as positive attitudes towards inclusion are amongst the strongest predictors of the success of the inclusion reforms (Avramidis \& Norwich, 2002; Forlin, 2010a). Effective inclusionary practices have been found to depend to a noticeable extent on the sentiments of teachers about the nature of disability and their perceived roles in supporting students with special education needs (Jordan, Schwartz, \& McGhie-Richmond, 2009). Prior experience and knowledge about students with disabilities have been found to be directly linked with more positive attitudes by teachers towards inclusion (Burke \& Sutherland, 2004).

A better understanding of teacher attitude towards inclusion can assist in improving the learning environment (Ross-Hill, 2009). Educators with apprehensive attitudes may use practices that promote exclusion rather than inclusion in their classrooms (Sharma, Forlin, \& Loreman, 2008). On the other hand, educators who hold positive attitudes towards inclusion tend to use teaching strategies that allow them to accommodate individual differences (Campbell, Gilmore, \& Cuskelly, 2003; Forlin, 2010a). 


\section{Concerns About Inclusion}

While educators' attitudes are important as potential predictors of success or failure of inclusion, equally important are their concerns about inclusion (Symeonidou \& Phtiaka, 2009). Agbenyega (2007) investigated attitudes and concerns of 100 teachers about teaching in inclusive classrooms in Ghana. He found that teachers' major concerns related to their lack of skills to effectively teach students with disabilities and lack of resources to accommodate individual differences, concluding that teachers' acceptance and commitment to implementing inclusion are likely to be affected by their attitudes and concerns. Changpinit, Greaves, and Frydenberg (2007) examined attitudes and concerns of 702 in-service educators to teach in inclusive classrooms in Thailand. They found that there was a significant and negative correlation between participants' attitudes and concerns. Participants who had relatively positive attitudes towards inclusive education were likely to have lower degree of concerns about it or vice versa. In a recent study, Forlin and Chambers (2011) expanded on the work by other researchers by examining how confidence in teaching students with disabilities and knowledge about local policies impacted pre-service teachers' attitudes and concerns. They reported that level of confidence and knowledge of legislation were positively and significantly correlated with attitudes towards including students with disabilities and conversely negatively correlated with concerns about inclusion. They also found, though, that increasing knowledge about legislation and policy related to inclusion, and improving confidence did not likewise address the participants' concerns or perceived stress associated with having students with disabilities in their classrooms.

\section{Measuring Attitudes and Concerns}

Much of the evidence obtained regarding pre-service teachers' sentiments and support for inclusive education has been anecdotal and gleaned from small samples in specific and fairly narrow contexts. Research in this area tends to be limited (Sze, 2009). Collection of reliable quantitative data is restricted to the use of a few instruments that have been designed for specific contexts, such as the development of a 24-item affective scale to measure school principals' attitudes towards the inclusion of students with disabilities in regular schools (Bailey, 2004). What has emerged from such data collection, nevertheless, is the impact that attitudes, sentiments towards students with disabilities, and perceived personal competence (concerns) have on a teacher's willingness to engage fully in providing appropriate inclusive curricula (Wilczenski, 1992, 1993). Research has also identified the importance of appropriate training to up-skill teachers and to better prepare new and practicing teachers for catering to the needs of an increasingly diverse student population (Chong, Forlin, \& Au, 2007; Florian 2009; Forlin, Loreman, Sharma, \& Earle, 2009; Loreman, Forlin, \& Sharma, 2007; Sharma \& Desai, 2002 Sharma et al., 2008). What seems to be missing, nonetheless, is an accurate and reliable way of measuring the usefulness of training in changing pre-service teachers' attitudes, sentiments, and concerns; in particular, a valid means of comparing their readiness and improvement across varied international contexts.

\section{Pre-service Teachers' Dispositions Towards Inclusion}

The focus of this paper is on education at the pre-service teacher level. The three psychometric constructs identified in the development of the SACIE scale pertain to aspects of inclusive education previously considered as central to the rationale underlying a teacher's beliefs and support for and engagement with inclusive practices (Sharma, Forlin, Loreman, \& Earle, 2006). If pre-service teachers are adequately prepared for inclusion then the need to 
provide this at the in-service level when teachers are immersed in a variety of other daily pressures relating to their jobs is possibly reduced.

Previous research employing three separate instruments (Sharma et al., 2006, 2008) has highlighted the need for a shorter, more user friendly scale to capture the multifaceted issues associated with beliefs about adopting inclusion in the classroom (i.e., a measure of sentiments or comfort levels when engaging with people with disabilities; their willingness to accept learners with differing levels of support need; and their concerns about implementing inclusive educational practices). Initial development by Loreman, Earle, Sharma, and Forlin (2007) produced the Sentiments, Attitudes, and Concerns about Inclusive Education (SACIE) scale, which was designed to measure these three fundamental constructs of inclusive education in pre-service teachers. This scale initially provided a 19-item measure of perceptions about inclusion.

The three constructs represented on the SACIE are critical to assess, as has been noted in other papers concerning the scale (see, for example, Loreman et al., 2007). Pre-service teacher sentiments towards people with disabilities clearly impacts the way in which they treat children who have disabilities in their classroom. This line of inquiry receives significant attention in the literature, with scales having been developed to measure this forming the basis of this feature of the SACIE (see Gething, 1991, 1994; Forlin, Jobling, \& Carroll, 2001). The second construct, attitudes towards inclusion, has possibly received the most attention in the research literature on pre-service teacher education and inclusion in recent years, with that research seeming to indicate that the more positive attitudes a pre-service teacher holds the more successful he or she is likely to be in practice (Avramidis, Bayliss, \& Burden, 2000; Avramidis \& Norwich, 2002). This aspect of the SACIE was initially based on notions developed from the Attitudes Towards Inclusive Education Scale (ATIES; Wilczenski, 1992) that reliably measured what was thought to be important aspects relating to attitude. The third feature of SACIE, concerns about inclusive education, is an important factor to have represented because of the continued high level of concerns in the educational community regarding the efficacy and practicality of inclusive education where teachers do not feel adequately well prepared (see for example, DeLuke, 2000; Sharma \& Desai, 2002). In measuring concerns it is possible for teacher educators to pinpoint areas in which anxiety exists, and therefore, take measures to try and alleviate that anxiety.

The purpose of the present study is to review the structure of the SACIE scale and assess its suitability across a variety of different cultures for measuring pre-service teachers' beliefs about the inclusion of students with disabilities in regular classes by: (a) conducting a series of statistical reviews of the SACIE scale using international data samples; (b) defining the SACIE scale based on the statistical data so as to produce a concise, clear, balanced, and statistically defensible research instrument; and (c) piloting the refined version of the SACIE scale on fresh international data samples in order to double-check the statistical defensibility of the instrument.

The original development of the SACIE reported in Loreman et al. (2007) involved the reduction of 60 items from three pre-existing scales to a 19-item scale. The three scales were the Attitudes Towards Inclusive Education scale (ATIES; Wilczenski, 1992); a modified version of the Interaction with Disabled Persons (IDP) scale (Forlin et al., 2001; Gething, 1991, 1994); and the Concerns about Inclusive Education Scale (CIES; Sharma \& Desai, 2002). These scales each employed the use of a multichotomous Likert-type format. The ATIES and IDP were 6-point scales and the CIES was a four-point scale (see Sharma et al., 2006).

The original 60 items from the IDP, ATIES, and CIES scales were reduced to a 19-item scale through statistical data reduction techniques based on an examination of international data, along with conceptual judgments made by a panel of international experts 
in inclusive education (Loreman et al., 2007). The resulting 19-item survey instrument solicited responses on a forced-choice 4-point Likert scale designed to eliminate a neutral midpoint response: $1=$ Strongly Agree, $2=$ Agree, $3=$ Disagree, and $4=$ Strongly Disagree . The Cronbach alpha value for the 19-item scale was 0.83. In addition to the 19 items used on the scale, the original survey included a number of demographic questions relating to age, gender, program of enrolment, and levels of education. These demographic questions were included as the researchers and panel of international experts believed that they would be helpful in investigating the topic in a more nuanced way. This has, in fact, proven to be the case. Findings using these variables, for example, have shown that female pre-service teachers are more likely to be positive in their responses to the SACIE than are their male counterparts (see Loreman \& Earle, 2007) along with other demographic variables that have been shown to produce significant differences in responses between groups.

\section{Method}

\section{Procedure}

For every phase of the validation process the scale was administered by one researcher in each region to pre-service teachers during the first half hour of their first lesson in a course on special or inclusive education. An administrative protocol was developed and followed to ensure consistency across sites. Data were all entered into a standard Statistical Package for the Social Science (SPSS) file with variables and coding categories preset. Once entered in each region, all files were combined into one data set.

\section{A Four-Stage Process}

The review of the SACIE scale followed a four-stage process. Stage one involved employing the 19-item SACIE and the first validation attempt. Stage two involved a revision of the scale based on the results of the previous iteration and the reduction from 19 to 15 items. Stage 3 involved the addition of eight new items for testing to strengthen the aspect of attitudes and improve the reliability of this factor. Stage four involved a final reduction and validation of the resultant 15-item SACIE scale. At all stages negatively worded items were reverse coded prior to calculation of reliability indices. Exploratory Factor Analysis (EFA) was employed to evaluate both the number of factors and the specific items to be included in the scale construct. The most common criteria for the selection of a cut-off point for factor inclusion in a construct are general "rules of thumb" established from theoretical considerations and from lessons learned from other successful efforts to scale behavioural phenomena in the social sciences (Netemeyer, Bearden, \& Sharma, 2003). The four criteria used in this study were (a) the eigenvalue greater than 1 rule, requiring that a given factor account for at least as much variance as can theoretically be accounted for by a single item (Cliff, 1988); (b) recognition of a well defined elbow in a scree plot, signifying a sharp reduction in the variance accounted for by a given factor as described by Cattell (1966); (c) consideration for the amount of variance explained by the final factor solution, whereby $50-60 \%$ of the variance should be accounted for by the selected factors, with a minimum of $5 \%$ for each retained factor (Hair, Black, Babin, \& Anderson, 2010); and (d) parallel analysis (Lautenschlager, 1989).

The data sets used throughout the refinement of the SACIE varied from 186 to 542 respondents. These sample data sets clearly exceed the recommended 100-200 respondent size suggested for narrowly defined scales such as SACIE with $\leq 20$ items (Clark \& Watson 1995; Haynes, Nelson, \& Blaine, 1999). Notably, the data set used to undertake the final validation of the SACIE far exceeded the sample size of 300 suggested by DeVellis (1991) as 
appropriate for even complex multidimensional constructs. Furthermore, this data set provided nearly 36 times the number of responses to items ratio recommended by Clark and Watson (1995). Most importantly, consideration of a priori established criteria was applied that restricted the theoretically derived factors to those that substantially informed the constructs under consideration.

\section{Results}

\section{Stage One: Initial Review}

Scale validation in Stage 1 consisted of a sample of 297 pre-service teachers from four institutions in four countries (Canada, Hong Kong, Australia, \& Singapore). These represented pre-service teachers preparing to work in either early childhood $(N=75)$, primary $(N=102)$, or secondary $(N=113)$ schools. The majority were women $(90 \%)$ and in the youngest age bracket $(84 \% \leq 25$ years).

Validation commenced with the application of EFA on the 19-item data set. Subsequently, a Varimax orthogonal rotation of the initial Principal Component Analysis (PCA) extraction was used to reduce inter-factor correlations and hence provide a simplified factor structure that would minimize the number of factors on which each item appeared. Varimax rotation with Kaiser normalization led to the establishment of three factors with eigenvalues greater than $1.0(4.28,4.01,3.34)$. Factor 1 accounted for $22.5 \%$ of the variance, Factor 2 accounted for $21.1 \%$, and Factor 3 accounted for $17.6 \%$. Examination of the scree plot indicated a substantial change in eigenvalues between Factor Components 3 and 4. Hence the scree plot supported the inclusion of three factors as relevant to the scale structure. This was confirmed by undertaking a parallel analysis to identify the number of factors to be retained. This has been recommended as being more robust and accurate compared to using eigenvalues and scree plot tests (Henson \& Roberts, 2006). The first four eigenvalues from the parallel analysis were $4.27,2.79,1.48$, and 1.11. Those from the real data were $6.61,3.23$, 1.79, and 0.96. Results indicated that the number of eigenvalues from the real data that had higher values than those obtained from a random sample using the parallel analysis was three. Thus three factors were retained.

Items found on two or more factors were considered candidates for exclusion as they are subject to misinterpretation and ambiguity to both respondents and interpreters of the scale alike (Netemeyer et al., 2003); thus, four items were deleted at this stage.

An oblique rotation (Promax with Kaiser normalization) was also used in Stage 1 of scale validation to provide supporting evidence for the items considered for elimination on the basis of the Varimax factor pattern coefficients. The Promax rotation, in that it characteristically allows factors to correlate, is perhaps theoretically more suited for item reduction, given the goal of EFA to identify the degree to which multi-dimensional factors correlate (Netemeyer et al., 2003). Eigenvalues greater than 1.0 were initially used for the extraction employing the Promax rotation. As in the Varimax analysis, item pairs containing missing values were excluded from the analysis and the final factor solution was reached in five iterations. Similar to the Varimax results, three factors with eigenvalues greater than 1.0 were generated from the Promax rotation (5.04, 4.84, 4.95). Although no measure of the proportion of variance explained by each factor is possible with the Promax rotation, given their correlated nature, the relatively high eigenvalues on five or more items per factor suggests that they collectively account for a large proportion of the scale construct.

EFA with the oblique Promax rotation produced results very similar to those obtained though the orthogonal Varimax rotation. The correlation matrix depicting the association between the fundamental domains of the three principal factors extracted through Promax rotation indicated correlations of $.23(p>0.10, d f=13)$ between Factors 1 and $2 ; .43(p>$ 
$0.10, d f=13)$ between Factors 1 and 3; and $.44(p>0.10, d f=13)$ between Factors 2 and 3. Clearly, there is no reason to believe there is any overlap in the theoretical constructs of the three factors $(\alpha=0.05)$ describing the SACIE scale. Inter-item consistency as determined by Cronbach's alpha represents the degree to which items appear on specific factors measure a common set of theoretical constructs.

A reported alpha value $(\alpha)$ of .83 for the reduced scale of 15 items by 297 respondents indicated a high level of inter-item consistency for psychometric scales of this type and sample size (Gable \& Wolf, 1993). Reliabilities of the three subscales were similarly calculated to be $\alpha=.86 ; \alpha=.86$; and $\alpha=.70$.

\section{Stage Two: Testing the Refined 15-Item SACIE}

Netemeyer et al. (2003) strongly recommended that a different set of data be used to confirm the validity of a scale. In keeping with this recommendation, a second population of 227 pre-service teachers was used to confirm the items and constructs of the refined 15-item SACIE scale. PCA was conducted on a newly generated data set of 227 pre-service teachers from three institutions in Hong Kong, Australia, and Singapore. Similar to the Stage 1 population, the participants represented pre-service teachers preparing to work in either primary $(N=115)$ or secondary $(N=112)$ schools. Furthermore, the vast majority were again women $(91 \%)$ and in the youngest age bracket $(83 \% \leq 25$ years). The exclusion of item pairs containing one or more null responses in place of the elimination of entire cases due to missing item responses was used to maximize sample retention and the number of iterations for convergence was set at 25 to ensure a valid stabilization of the factor structure.

As with the earlier procedures, the sample exceeded the recommended data size of 100-200 cases considered appropriate for broadly defined scales (Clark \& Watson, 1995; Haynes et al., 1999). It also provided 15 times the number of responses per item compared to the recommended 5-10 responses per item suggested by Clark and Watson (1995) and Hair et al. (2010).

Subsequent PCA using a Promax rotation produced both a factor pattern matrix to best determine the item membership of the factors and a factor structure matrix on which to evaluate the relative importance of the 15 items on each factor construct. The factor pattern and structure confirmed the three factors identified in the initial EFA. Again all three factors exhibited eigenvalues greater than $1(4.91,4.60,1.98)$. Furthermore, inter-correlations between factors were less than 0.30 , suggesting that the three components of the construct now represented reasonably independent issues related to inclusive education.

Ideally, all psychometric scales should possess subscales or factors that measure completely independent phenomena in a well balanced, equitable manner (Netemeyer et al., 2003). Indeed, unidimensionality is considered by many to be a prerequisite to scale reliability and validity (e.g., Cortina, 1993; Gerbing \& Anderson, 1988; Hattie, 1985; Schmitt, 1996). Notably, the most common measure of internal consistency of scales, Cronbach's (1951) coefficient alpha is meaningful only for a unidimensional set of items (Clark \& Watson, 1995; Cortina, 1993). This version of the SACIE scale possessed three subscales which were unequivocally unidimensional in nature, but they lacked balance between the factors. In particular, the scale at this stage of development was under represented in items related to attitudes towards inclusive education.

Regarding the items comprising the three factor structure of the refined SACIE construct, seven items were above the designated substantial level of .40 on Factor 1 (Sentiments, .78 to .62). With respect to Factor 2, there were two items (Attitudes, .77 to .75) and for Factor 3, six items that had substantial factor pattern coefficients (Concern, .83 to .63). The correlation coefficients measuring the degree of association between factors were all less 
than .30. Consequently, the three factors all appear to measure independent phenomena, thus accomplishing one of the major goals of scale development, to reduce ambiguity in the interpretation of the scale (Netemeyer et al., 2003). The sum of eigenvalues informing the three subscales that measured the sentiments, attitudes, and concerns towards inclusive education also suggested that Factor 2 (attitudes) was indeed inadequately represented.

The reliabilities of the scales were calculated for the seven items in Factor $1(\alpha=.83)$ and for the six items in Factor $3(\alpha=.85)$. These demonstrated a very high level of inter-item consistency for both factors. As noted earlier, the number of items in the second factor $(N=2)$ was deemed too small to generate an accurate reliability. Despite the apparent weakness of the structure of the second factor, whole-scale reliability, considering the combined contribution of all three factors, was acceptable $(\alpha=.85)$.

\section{Stage Three: Revision and Further Testing of the SACIE Scale}

Disproportionate representation among the three constructs identified in the results of the PCA in Stage 2 was problematic. Consequently, the next stage was to improve the scale by adding eight new items that would potentially address this issue, bolstering the attitudes component of the scale. Based on theoretical constructs related to peoples' attitudes towards phenomena, several newly formulated questions were developed and introduced to the survey to balance the contribution of the three constructs. The items were drawn from the original ATIES scale which specifically measured participants' attitudes towards inclusion. The resulting 23-item survey was administered to a new population of 186 Canadian and Hong Kong pre-service teachers to evaluate whether these could provide an equal weighting to all three components of the nomological network, thus strengthening the third factor.

Exploratory factor analysis was carried out to identify a plausible factor structure for the new 23-item survey data. Factoring was conducted using a PCA of a correlation matrix of all item pairs followed by Varimax rotation of the initial matrix to simplify the factor structure. Communality among the components of the scale was evaluated by calculating the correlation coefficients between factors. Notably, the resulting three factor structure which produced the most consistent reliabilities consisted of 15 items and exhibited equal representation between the three scale components identified as sentiments, attitudes, and concerns related to inclusive education. The relative proportion of variance explained by three factors was $23.4 \%, 19.4 \%$, and $15.5 \%$, respectively.

\section{Stage Four: Final Validation}

Final confirmation of the validity of the new 15-item three-factor structure of the SACIE scale was conducted using a further data set of 542 pre-service teachers from nine institutions located in four countries (Canada, Hong Kong, India, and the United States). Like the other data sets, the respondents were principally training to become either a primary $(35 \%)$ or secondary school teacher $(46.8 \%)$ and most were relatively young $(85.7 \%)$ and women $(87.3 \%)$. Confirmation of the nomological network comprising the sentiments, attitudes, and concerns of pre-service teachers was accomplished through PCA of a correlation matrix followed by an Orthogonal Rotation (Varimax; see Table 1). Internal reliability as measured by Cronbach's alpha was acceptable for both the combined SACIE scale $(\alpha=.74)$ and the individual subscales of sentiments $(\alpha=.75)$, attitudes $(\alpha=.67)$, and concerns $(\alpha=.65)$. It is important to highlight that the alpha values for the attitudes and concern subscales were slightly lower than desired but still acceptable to measure these types of social constructs (DeVellis, 1991). The total proportion of variance explained for the scale was $47.31 \%$. Researchers using the instrument should take into account that approximately half of the variation in responses is caused by unknown or inherent variability. The independent nature 
of all three subscales was confirmed by the reported non-associations seen in Table 2 .

Table 1

The Final Three-Factor SACIE-R Structure Based on a 15-Item Survey Administered to Pre-Service Teachers from Canada, United States, India, and Hong Kong $(N=542)$

\begin{tabular}{|c|c|c|c|}
\hline Item & $\begin{array}{c}\text { Factor } 1 \\
\text { (Sentiments) }\end{array}$ & $\begin{array}{l}\text { Factor } 2 \\
\text { (Attitudes) }\end{array}$ & $\begin{array}{l}\text { Factor } 3 \\
\text { (Concerns) }\end{array}$ \\
\hline $\begin{array}{l}\text { I find it difficult to overcome my initial shock when meeting people with severe } \\
\text { physical disabilities. }\end{array}$ & .730 & & \\
\hline I am afraid to look a person with a disability straight in the face. & .727 & & \\
\hline $\begin{array}{l}\text { I tend to make contacts with people with disabilities brief and I finish them as } \\
\text { quickly as possible. }\end{array}$ & .666 & & \\
\hline I would feel terrible if I had a disability. & 651 & & \\
\hline I dread the thought that I could eventually end up with a disability. & .347 & & 164 \\
\hline $\begin{array}{l}\text { Students who have difficulty expressing their thoughts verbally should be in } \\
\text { regular classes }\end{array}$ & & .746 & 107 \\
\hline Students who frequently fail exams should be in regular classes. & -.125 & .746 & \\
\hline $\begin{array}{l}\text { Students who need an individualized academic program should be in regular } \\
\text { classes. }\end{array}$ & & .722 & \\
\hline Students who are inattentive should be in regular classes. & -.126 & .719 & \\
\hline $\begin{array}{l}\text { Students who require communicative technologies (for example Braille and } \\
\text { sign language) should be in regular classes. }\end{array}$ & .299 & .629 & \\
\hline $\begin{array}{l}\text { I am concerned that my workload will increase if I have students with } \\
\text { disabilities in my class. }\end{array}$ & .253 & & .729 \\
\hline $\begin{array}{l}\text { I am concerned that it will be difficult to give appropriate attention to all } \\
\text { students in an inclusive classroom. }\end{array}$ & & & .704 \\
\hline $\begin{array}{l}\text { I am concerned that I will be more stressed if I have students with disabilities in } \\
\text { my class. }\end{array}$ & .129 & .394 & .650 \\
\hline $\begin{array}{l}\text { I am concerned that students with disabilities will not be accepted by the rest of } \\
\text { the class. }\end{array}$ & & -.125 & .544 \\
\hline $\begin{array}{l}\text { I am concerned that I do not have knowledge and skills required to teach } \\
\text { students with disabilities. }\end{array}$ & & .314 & .422 \\
\hline Proportion of Variance Explained & 16.75 & 17.22 & 13.34 \\
\hline
\end{tabular}

Table 2

Component Correlation Matrix for the SACIE-R Three-Factor Solution of the Final SACIE-R Scale ( $N=542)$

\begin{tabular}{llll}
\hline Component & Factor 1 (Sentiments) & Factor 2 (Attitudes) & Factor 3 (Concerns) \\
\hline Factor 1 (Sentiments) & 1.000 & 1.000 & \\
Factor 2 (Attitudes) & .050 & .197 & 1.000 \\
Factor 3 (Concerns) & .316 & & \\
\hline
\end{tabular}

Note. All correlation coefficients associated with $p \geq 0.10$.

\section{Conclusion}

Preparing pre-service teachers to work in inclusive schools requires universities and colleges to ensure that their curriculum covers sufficient detail to enable newly graduating teachers to cater for the increasing diversity of student needs. Teacher education must also provide a relevant pedagogy to enable pre-service teachers to develop appropriate dispositions that will support an inclusive philosophy (Florian, 2009). In many instances, pre-service teachers' conceptualizations of inclusion are problematic and teacher preparation courses fail to take into account their sentiments, attitudes, and concerns (Symeonidou \& Phtiaka, 2009).

This study was undertaken to finalise the development of the SACIE scale as a measurement tool for identifying pre-service teachers' attitudes towards inclusion and their sentiments and concerns about inclusive education. The three psychometric constructs identified in the final revised version of the scale (re-named as SACIE-R) pertained to aspects 
of inclusive education previously considered as central to the rationale underlying a teacher's beliefs and support for and engagement with inclusive practices (Loreman et al., 2007). This combined construct necessarily includes components to evaluate sentiments about engaging with people with disabilities (Factor 1, Sentiments), acceptance of learners with different support needs (Factor 2, Attitudes), and their concerns about inclusive education (Factor 3, Concerns). Illustrative items for each of these theoretical constructs - the nomological network - appear to provide sufficient depth to initially confirm the refined scale. External validity of the scale, however, needs to be established. Future researchers may like to explore how well this scale correlates with other existing scales that measure attitude, sentiments, or concerns. The scale also lends itself to be validated with other populations such as in-service teachers. The main purpose of this paper was to articulate how the scale was developed and refined and to report on its psychometric properties. This paper does not discuss how participants from various countries differ in their sentiments, attitudes, and concerns as this aspect is beyond the scope of the study and is discussed in detail elsewhere (Forlin et al., 2009; Sharma et al., 2008).

To enable a range of independent variables to be considered, the final version of the demographics page was expanded to seek data on other variables including the level of training pre-service teachers had previously received in educating students with disabilities, their experience in teaching a student with a disability, their knowledge of disability policy, and their confidence level in teaching (see Appendix). It is anticipated that when employing the SACIE-R this section should be modified to accommodate the needs of local contexts.

The decision to negatively gear two factors was based on the consideration that the normal way of expressing concerns is through the negative voice, while attitudes are generally expressed in either voice. Conversely, all attitude questions were worded such that the numerical scale reflected positive sentiment towards inclusion.

While Factor 1 (Sentiments; e.g., "I dread the thought that I could eventually end up with a disability") and Factor 3 (Concerns; e.g., "I am concerned that my workload will increase if I have students with disabilities in my class") remained negatively geared-and required reverse coding before analyzing in order to transform the responses to a common positive direction of scale - the consistency of the polarity within individual factors was retained to reduce ambiguity in the interpretation of the questions as recommended by Netemeyer et al. (2003). The order of the anchor points on the numerical scale was applied to reflect a higher mean being associated with more positive attitudes $(1=$ Strongly Disagree; 2 =Disagree; 3 =Agree, and; $4=$ Strongly Agree). Finally, the order of the items in the survey were randomly assigned to ensure a level of objectivity as suggested by Bailey (2004), thus contributing to a reduction in proximity effect and a lessening of the risk that people will respond in the same way to similar adjacent items.

This further refinement and initial validation of the 15-item scale provides early support for the SACIE-R. Supplementary validation, however, across a range of contexts at both pre- and post-training stages is necessary to provide on-going support for the scale's acceptance and broaden its appeal as a relatively easy to administer international tool. It is fully acknowledged that it is challenging to change pre-service teachers' sentiments, attitudes, and concerns about inclusion (Jordan et al., 2009), but the provision of a scale that can go some way towards identifying what these beliefs are will provide useful information for developing programs that target these.

The SACIE-R scale also provides the potential to assess changes in perceptions during pre-service training to enable teacher educators to identify whether their courses are providing an appropriate means of improving attitudes and sentiments towards inclusion and lessening their concerns. It is, therefore, posited that the SACIE-R may yield valuable information for assisting teacher education institutions in preparing more specific training 
programs that can address the individual needs and beliefs of different cohorts of pre-service teachers, and for assessing whether the targeted aspects of inclusive education have been appropriately addressed.

Similar to other scales such as the Attitude Toward Mainstreaming Scale (Berryman \& Neal, 1980), which since its early development has continued to undergo re-evaluation of its factor structure and validity (Green \& Harvey, 1983; Wilczenski, 1992), it is anticipated that the SACIE-R scale will similarly be exposed to further rigorous assessment to ensure it retains its currency and applicability across as broad a range of jurisdictions as possible. There are initial indications, however, of some limitations that should be investigated further by researchers using the instrument. As noted, the percentage of variance explained in the final scale of less than $50 \%$ should be further scrutinized, along with the internal reliability of the attitudes and concerns subscales which fall slightly below the ideal.

In conclusion, there appears to be adequate evidence to suggest that this refined SACIE-R scale currently possesses sufficient strength to justify its use in identifying changes in pre-service teachers' dispositions towards inclusion, their sentiments about engaging with people with a disability, their attitudes towards accepting learners with different needs in regular classrooms, and their concerns about implementing inclusive practices.

\section{References}

Agbenyega, J. (2007). Examining teachers' concerns and attitudes to inclusive education in Ghana. International Journal of Whole Schooling, 3(1), 41-56. Retrieved from http:// www.wholeschooling.net/Journal_of_Whole_Schooling/IJWSIndex.html

Alghazo, E. M., \& Gaad, E. E. N. (2004). General education teachers in the United Arab Emirates and their acceptance of the inclusion of students with disabilities. British Journal of Special Education, 31(2), 94-99. doi:10.1111/j.0952-3383.2004.00335.x

Avramidis, E., Bayliss, P., \& Burden, R. (2000). Student teachers' attitudes towards the inclusion of children with special educational needs in the ordinary school. Teaching and Teacher Education, 16(2), 277-293. doi:10.1016/S0742-051X(99)00062-1

Avramidis, E., \& Norwich, B. (2002). Teachers' attitudes towards integration/inclusion: A review of literature. European Journal of Special Needs Education, 17(2), 129-147. doi:10.1080 /08856250210129056

Bailey, J. (2004). The validation of a scale to measure school principals' attitudes towards the inclusion of students with disabilities in regular schools. Australian Psychologist, 39, 76-87. doi:10.1080 /00050060410001660371

Berryman, J. D., \& Neal, W. R. Jr. (1980). The cross validation of the attitudes toward mainstreaming scale (ATMS). Educational \& Psychological Measurement, 40, 469-474. doi:10.1177 $/ 001316448004000227$

Burke, K., \& Sutherland, C. (2004). Attitudes towards inclusion: Knowledge vs experience. Education, $125(2), 163-172$.

Calgary Board of Health. (2008). Healthy diverse populations. Retrieved from http://www.crhahealth.ab.ca /programs/diversity/diversity_resources/definitions/definitions_main.htm

Campbell, J., Gilmore, L., \& Cuskelly, M. (2003). Changing student teachers' attitudes towards disability and inclusion. Journal of Intellectual and Developmental Disability, 28(4), 369-379. doi:10.1080 /13668250310001616407

Cattell, R. B. (1966). The meaning and strategic use of factor analysis. In R. B. Cattell (Ed.), Handbook of multivariate experimental psychology (pp. 131-206). Chicago, IL: Rand McNally.

Changpinit, S., Greaves, D., \& Frydenberg, E. (2007). Attitudes, knowledge, concerns, and coping strategies regarding inclusive education in community of Thai educators, The $1^{\text {st }}$ International conference on Educational Reform, Mahasarakham University, Thailand. Retrieved from http:// www.icer.msu.ac.th/ICER2007/paper/CI03.pdf

Chong, S., Forlin, C., \& Au, M. L. (2007). The influence of an inclusive education course on attitude change of pre-service secondary teachers in Hong Kong. Asia Pacific Journal of Teacher Education, 35(2), 161-179. doi:10.1080/13598660701268585

Clark, L. A., \& Watson, D. (1995). Constructing validity: Basic issues in scale development. Journal of 
Psychological Assessment, 7(3), 309-319. doi:10.1037/1040-3590.7.3.309

Cliff, N. (1988). The eigenvalue-greater-than-one rules and reliability of components. Psychological Bulletin, 103(2), 276-279. doi:10.1037/0033-2909.103.2.276

Cortina, J. M. (1993). What is coefficient alpha? An examination of theory and application. Journal of Applied Psychology, 78, 98-104. doi:10.1037/0021-9010.78.1.98

Cronbach, L. J. (1951). Coefficient alpha and the internal structure of tests. Psychometrika, 16, 297-334. doi:10.1007/BF02310555

DeLuke, S. (2000). A model for merging programs in special education and elementary education: The inclusive education teacher preparation program at the College of Saint Rose. In L. Sherry \& F. Spooner (Eds.), Unified teacher preparation programs for general and special educators. Reston, VA: National Council for Exceptional Children.

Department for Education. (2001). Special educational needs code of practice. Department for Education: United Kingdom.

DeVellis, R. F. (1991). Scale development: Theory and applications. Newbury Park, CA: Sage.

Florian, L. (2009). Preparing teachers to work in 'school for all'. Teaching and Teacher Education, 25(4), 533-534. doi:10.1016/j.tate.2009.02.004

Forlin, C. (2008). Education reform for inclusion in Asia: What about teacher education? In C. Forlin \& M. G. J. Lian (Eds.), Reform, inclusion \& teacher education: Towards a new era of special education in the Asia-Pacific region (pp. 61-73). Abingdon: Routledge.

Forlin, C. (2010a). Re-framing teacher education for inclusion. In C. Forlin (Ed.), Teacher education for inclusion: Changing paradigms and innovative approaches (pp. 3-10). Abingdon: Routledge.

Forlin, C., \& Chambers, D. (2011). Teacher preparation for inclusive education: Increasing knowledge but raising concerns. Asia Pacific Journal of Teacher Education, 39(1) 17-32. doi:10.1080 /1359866X.2010.540850

Forlin, C., Jobling, A., \& Carroll, A. (2001). Pre-service teachers' discomfort levels toward people with disabilities. Journal of International Special Needs Education, 4, 32-38.

Forlin, C., Loreman, T., Sharma, U., \& Earle, C. (2009). Demographic differences in changing pre-service teachers' attitudes, sentiments and concerns about inclusive education. International Journal of Inclusive Education, 13(2), 195-209. doi:10.1080/13603110701365356

Gable, R. K., \& Wolf, M. B. (1993). Instrument development in the affectiveness domain: Measuring attitudes and values in corporate and school settings. Boston, MA: Kluwer Academic Publishers.

Gause, C. P. (2011). Diversity, equity, and inclusive education: A voice from the margins. Rotterdam, Netherlands: Sense.

Gerbing, D. W., \& Anderson, J. C. (1988). An updated paradigm for scale development incorporating unidimensionality and its assessment. Journal of Marketing Research, 25, 186-192. Retrieved from mpdev.marketingpower.com

Gething, L. (1991). The interaction with disabled persons scale: Manual and kit. Sydney: University of Sydney.

Gething, L. (1994). The interaction with disabled persons scale. Journal of Social Behavior and Personality, 9(5), 23-42.

Government of the United States of America. (2001). No child left behind act. United States Government: Washington, DC.

Green, K., \& Harvey, D. (1983). Cross-cultural validation of the attitudes toward mainstreaming scale. Educational \& Psychological Measurement, 43, 1255-1261. doi:10.1177/001316448304300437

Hair, J. F., Black, W. C., Babin, B. L., \& Anderson. (2010). Multivariate data analysis (7th ed.). Englewood Cliffs, NJ: Prentice Hall.

Harvey, M. W., Yssel, N., Bauserman, A. D., \& Merbler, J. B. (2010). Preservice teacher preparation for inclusion. Remedial \& Special Education, 31(1), 24-33. doi:10.1177/0741932508324397

Hattie, J. (1985). Methodological review: Assessing unidimensionality of tests and items. Applied Psychological Measurement, 9, 139-164. doi:10.1177/014662168500900204

Haynes, S., Nelson, N. K., \& Blaine, D. (1999). Psychometric issues in assessment research. In P. C. Kendall, J. N. Butcher, \& G. Holmbeck (Eds.), Handbook of research methods in clinical psychology (pp. 125-154). New York, NY: John Wiley \& Sons.

Henson, R. K., \& Roberts, K. (2006). Use of exploratory factor analysis in published research: Common errors and some comment on improved practice. Educational and Psychological Measurement, 66(3), 393-416. doi:10.1177/0013164405282485 
Jordan, A. (2007). Introduction to inclusive education. Mississauga, ON: Wiley \& Sons.

Jordan, A., Schwartz, E., \& McGhie-Richmond, D. (2009). Preparing teachers for inclusive classrooms. Teaching and Teacher Education, 25(4), 535-542. doi:10.1016/j.tate.2009.02.010

Lautenschlager, G. J. (1989). A comparison of alternatives to conducting Monte Carlo analyses for determining parallel analysis criteria. Multivariate Behavioural Research, 24(3), 365-395. doi:10.1207 /s15327906mbr2403 6

Loreman, T. (2009, spring). Straight talk about inclusive education. The Cass Connection, 43-47.

Loreman, T., \& Earle, C. (2007). The development of attitudes, sentiments, and concerns about inclusive education in a content-infused Canadian teacher preparation program. Exceptionality Education Canada, 17(1), 85-106. Retrieved from http://ejournals.library.ualberta.ca/index.php/eei

Loreman, T., Earle, C., Sharma, U., \& Forlin, C. (2007). The development of an instrument for measuring pre-service teachers' sentiments, attitudes, and concerns about inclusive education. International Journal of Special Education, 22(2), 150-159. Retrieved from http://www .internationaljournalofspecialeducation.com

Loreman, T., Forlin, C., \& Sharma, U. (2007). An international comparison of pre-service teacher attitudes towards inclusive education. Disability Studies Quarterly, 27(4). Retrieved from http://www .dsq-sds.org/article/view/53/53

Netemeyer, R. G., Bearden, W. O., \& Sharma, S. (2003). Scaling procedures: Issues and applications. Thousand Oaks, CA: Sage.

Richards, H., Brown, A., \& Forde, T. (2006). Practitioner brief. Addressing diversity in schools: Culturally responsive pedagogy. AZ:.National Center for Culturally Responsive Educational Systems (NCCRESt), Arizona State University.

Ross-Hill, R. (2009). Teacher attitude towards inclusion practices and special needs students. Journal of Research in Special Educational Needs, 9(3), 188-198. doi:10.1111/j.1471-3802.2009.01135.x

Schmitt, N. (1996). Uses and abuses of coefficient alpha. Psychological Assessment, 8, 350-353. doi:10.1037/1040-3590.8.4.350

Sharma, U., \& Desai, I. (2002). Measuring concerns about integrated education in India. Asia \& Pacific Journal on Disability, 5(1), 2-14. Retrieved from http://www.dinf.ne.jp/doc/english/asia/resource /z00ap/vol5nol/measure.html

Sharma, U., Ee, J., \& Desai, I. (2003). A comparison of Australian and Singaporean pre-service teachers' attitudes and concerns about inclusive education. Teaching and Learning, 24(2), 207-217. Retrieved from http://repository.nie.edu.sg/jspui/bitstream/10497/322/1/TL-24-2-207.pdf

Sharma, U., Forlin, C., \& Loreman, T. (2008). Impact of training on pre-service teachers' attitudes and concerns about inclusive education and sentiments about persons with disabilities. Disability \& Society, 23(7), 773-785. doi:10.1080/09687590802469271

Sharma, U., Forlin, C., Loreman, T., \& Earle, C. (2006). Pre-service teachers' attitudes, concerns and sentiments about inclusive education: An international comparison of the novice pre-service teacher. International Journal of Special Education, 21(2), 80-93. Retrieved from http:// www.internationaljournalofspecialeducation.com

Symeonidou, S., \& Phtiaka, H. (2009). Using teachers' prior knowledge, attitudes and beliefs to develop in-service teacher education courses for inclusion. Teaching \& Teacher Education, 25(4), 543-550. doi:10.1016/j.tate.2009.02.001

Sze, S. (2009). A literature review: Pre-service teachers' attitudes toward students with disabilities. Education, 130(1), 53-56.

Talmor, R., Reiter, S., \& Feigin, N. (2005). Factors relating to regular education teacher burnout in inclusive education. European Journal of Special Needs Education, 20(2), 215-229. doi:10.1080/08856250500298012

UNESCO. (1990, March). World declaration on education for all: Meeting basic learning needs. Paper presented at the World Conference on Education for All, Jomtein, Thailand. Abstract retrieved from http://www.un-documents.net/jomtien.htm

UNESCO. (1994). The Salamanca statement and framework for action on special needs education. Adopted by the world conference on special needs education: access and equity. Paris: Author.

UNESCO. (2000, April). Dakar framework for action, education for all: Meeting our collective commitments. Paper presented at the World Education Forum, Dakar, Senegal.

United Nation. (2006). Convention on the right of persons with disabilities. Retrieved from http:// www.un.org/disabilities/convention/conventionfull.shtml 
United States Department of Education. (2004). Individuals with Disabilities Improvement Act. United States Government: Washington, DC.

Voltz, D. L., \& Collins, L. (2010). Leaders licensure consortium contexts: Beyond the Council for Exceptional Children and the interstate school. Teacher Education and Special Education. doi: $10.1177 / 0888406409356676$

Wilczenski, F. L. (1992). Reevaluating the factor structure of the attitudes toward mainstreaming scale. Educational \& Psychological Measurement, 52, 499-504. doi:10.1177/0013164492052002026

Wilczenski, F. L. (1993). Changes in attitudes toward mainstreaming among undergraduate education pre-service teachers. Education Research Quarterly, 17(1), 5-17.

Woolfson, L. M., \& Brady, K. (2009). An investigation of factors impacting on mainstream teachers' beliefs about teaching students with learning difficulties. Educational Psychology, 29(2), 221-238. doi: $10.1080 / 01443410802708895$

\section{Authors' Note}

Correspondence concerning this article should be addressed to Professor Chris Forlin, Dept. Special Education \& Counselling, D2-2F-14, Hong Kong Institute of Education, 10, Lo Ping Road, Tai Po, NT, Hong Kong. Email: cforlin@ied.edu.hk

The authors wish to acknowledge the contribution of Paul M. Ajuwon of Missouri State University and Elga Andriana of Monash University for providing some of the data for the development process. 


\section{Appendix}

\section{The Sentiments, Attitudes, and Concerns about Inclusive Education Scale Revised (SACIE-R)}

In order to be able to track pre and post data please include your student number. This will not be used to identify individuals.

Student ID:

Pre-Test

Post-Test

Please $\checkmark$ on the line as appropriate.

A. I am teaching / training to teach in:

1. Early Childhood

2. Primary/Elementary

B. I am: 1. Male

C. What is your age?
3. Secondary

4. Special Education

2. Female
1. 25 years or below
3. $36-45$ years
2. 26-35 years

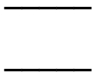
4. 46 years or above

D. My highest level of education completed is:
1. Secondary School or its equivalent
3. Master's Degree
2. Bachelor's Degree or its equivalent
4. Other, please specify

E. I have had significant/considerable interactions with a person with a disability:

1. Yes 2.No

F. I have had the following level of training on educating students with disabilities:
1. None
2. Some
3. High (at least 40hrs)

G. My knowledge of the local legislation or policy as it pertains to children with disabilities is:
1. None
2. Poor
3. Average
4. Good
5. Very Good

H. My level of confidence in teaching students with disabilities is:
1. Very Low
2. Low
3. Average
4. High
5. Very High

I. My level of experience teaching a student with a disability is:
1. Nil
2. Some
3. High (at least 30 full days) 
The following statements pertain to inclusive education which involves students from a wide range of diverse backgrounds and abilities learning with their peers in regular schools that adapt and change the way they work in order to meet the needs of all.

Please circle the response which best applies to you.

\begin{tabular}{|l|l|l|l|}
\hline SD & D & A & SA \\
\hline Strongly Disagree & Disagree & Agree & Strongly Agree \\
\hline
\end{tabular}

\begin{tabular}{|c|c|c|c|c|c|}
\hline 1 & $\begin{array}{l}\text { I am concerned that students with disabilities will not be } \\
\text { accepted by the rest of the class. }\end{array}$ & SD & D & A & SA \\
\hline 2 & $\begin{array}{l}\text { I dread the thought that I could eventually end up with a } \\
\text { disability. }\end{array}$ & SD & D & A & SA \\
\hline 3 & $\begin{array}{l}\text { Students who have difficulty expressing their thoughts verbally } \\
\text { should be in regular classes. }\end{array}$ & SD & D & A & SA \\
\hline 4 & $\begin{array}{l}\text { I am concerned that it will be difficult to give appropriate } \\
\text { attention to all students in an inclusive classroom. }\end{array}$ & SD & D & A & SA \\
\hline 5 & $\begin{array}{l}\text { I tend to make contacts with people with disabilities brief and I } \\
\text { finish them as quickly as possible. }\end{array}$ & SD & D & A & SA \\
\hline 6 & Students who are inattentive should be in regular classes. & SD & D & A & SA \\
\hline 7 & $\begin{array}{l}\text { I am concerned that my workload will increase if I have } \\
\text { students with disabilities in my class. }\end{array}$ & SD & D & A & SA \\
\hline 8 & $\begin{array}{l}\text { Students who require communicative technologies (e.g. } \\
\text { Braille/sign language) should be in regular classes. }\end{array}$ & SD & D & A & SA \\
\hline 9 & I would feel terrible if I had a disability. & SD & D & A & SA \\
\hline 10 & $\begin{array}{l}\text { I am concerned that I will be more stressed if I have students } \\
\text { with disabilities in my class. }\end{array}$ & SD & D & A & SA \\
\hline 11 & I am afraid to look directly at a person with a disability. & SD & D & A & SA \\
\hline 12 & $\begin{array}{l}\text { Students who frequently fail exams should be in regular } \\
\text { classes. }\end{array}$ & SD & D & A & SA \\
\hline 13 & $\begin{array}{l}\text { I find it difficult to overcome my initial shock when meeting } \\
\text { people with severe physical disabilities. }\end{array}$ & SD & D & A & SA \\
\hline 14 & $\begin{array}{l}\text { I am concerned that I do not have the knowledge and skills } \\
\text { required to teach students with disabilities. }\end{array}$ & SD & D & A & SA \\
\hline 15 & $\begin{array}{l}\text { Students who need an individualized academic program } \\
\text { should be in regular classes. }\end{array}$ & SD & D & A & SA \\
\hline
\end{tabular}

THANK YOU FOR COMPLETING THIS QUESTIONNAIRE 